\title{
Correction to: Communication between deep sea container terminals and hinterland stakeholders: information needs and the relevance of information exchange
}

\author{
Bart Wiegmans $^{1} \cdot$ Ilse Menger $^{1} \cdot$ Behzad Behdani $^{2} \cdot$ \\ Bart van Arem ${ }^{1}$
}

Published online: 26 October 2017

(C) Macmillan Publishers Ltd 2017

\section{Correction to: Marit Econ Logist \\ DOI 10.1057/s41278-017-0071-y}

We regret that one of the author's names (Ilse Menger) was misspelt in the article. The original article stated the authors as follows:

Bart Wiegmans, Isle Menger, Behzad Behdani and Bart van Arem.

In fact, the authors should have been listed as follows:

Bart Wiegmans, Ilse Menger, Behzad Behdani and Bart van Arem

We apologise for this oversight.

The online version of the original article can be found under doi:10.1057/s41278-017-0071-y.

Behzad Behdani

Behzad.behdani@wur.nl

1 Department of Transport and Planning, Delft University of Technology, Delft, The Netherlands

2 Operations Research and Logistics, Wageningen University and Research, Hollandseweg 1, $6706 \mathrm{KN}$ Wageningen, The Netherlands 